My Student Elective

\title{
First Western medical student to study in China?
}

\author{
ROGER B HOWELLS
}

Since 1949 China has experienced great sociopolitical change. The first faltering steps, the "great leap forward," and the regressive cultural revolution have been followed by the present "reconstruction," a period of modernisation in which the country has emerged from isolation. During all this time Chinese medicine has developed along its own independent path, taking direction from Mao's teaching that:

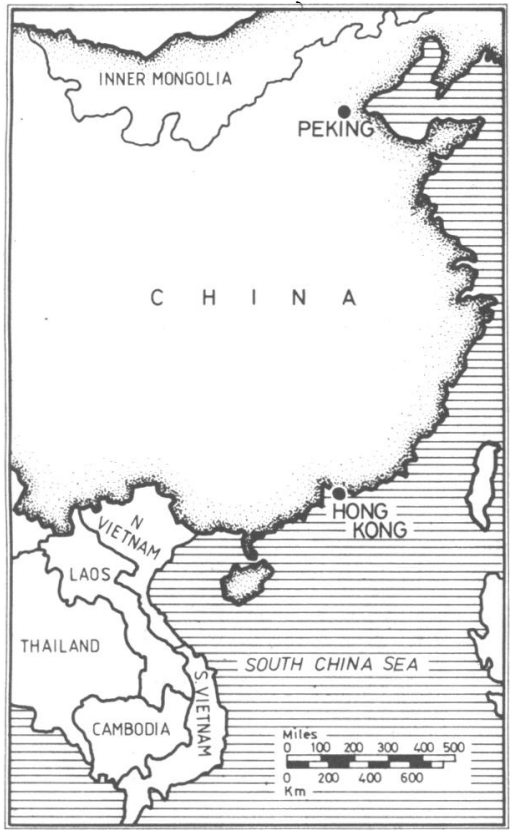

"Chinese medicine and pharmacology are a great treasure-house, and efforts should be made to exploit them and raise them to a higher level."

My interest in China and in Chinese medicine in particular stems from a memorable evening at the London Hospital in which a filmed lecture by the late Dr Joshua Horn was shown. In his lecture, delivered in New York in 1971, Joshua Horn gave a fascinating account of the experience and lessons of 15 years of medical practice in China. ${ }^{1}$ Since 1971 medical delegations from many countries have observed Chinese medical practice-the early accounts being more general in nature than the recent observations, which have commented on specific topics. Few, however, have had the opportunity to conduct an in-depth study of specific medical problems from original sources-an approach likely to give fresh perspectives on the intransigent problems facing Western medical science. The object of my visit was to conduct a detailed study of the Chinese approach to one such problem-schizophrenia. For this purpose I went to work with Professor Shen Yucun and her colleagues at the Institute of Mental Health, Peking Medical College.

School of Clinical Medicine, University of Cambridge ROGER B HOWELLS, BSC, medical student

\section{Arrival in Peking}

Crossing into China from Hong Kong is an interesting experience. As the train snakes through the hills of the New Territories one leaves behind a world of intense commercial pressure with its architectural wonders and street-corner beggars to arrive in a world of apparent material equality-a world of blue and green uniformity. In both Canton and Peking, however, I was struck by evidence of a recent and profound political change. On the streets party slogans are being removed or replaced by advertisements. During my stay the huge portraits of Marx, Engels, Lenin, and Stalin were removed from Tian'anmen Square. The blue and green Mao-jackets are giving way to T-shirts and sunglasses. While not wishing for a return to the past, one cannot but hope the Chinese in their enthusiasm for modernisation will be discerning about what they accept from the West; one hopes the presence of Coca Cola was not the signal for consumerism.

I arrived in Peking after a three-hour flight from Canton. It was mid-August and extremely hot in Peking, though mercifully less humid than in the south. I was greeted by the college authorities who explained that I was the first medical student from the West to come for prolonged study. Not the first foreign student, however, for China offers medical scholarships to developing countries, and I was to share accommodation with students from many nations. At my base, the Institute of Mental Health, I was welcomed by the senior psychiatrists who had made arrangements for me to see the clinical and research activities relating to schizophrenia. The staff had a good grasp of English and welcomed the opportunity to practise it. I found it amusing that the first schizophrenic patient I saw replied in impeccable English. By way of reciprocation for their ready help, I offered to give lectures on areas of psychology in which I had experience. The offer was taken up with enthusiasm and Wednesday afternoons put aside for the purpose.

\section{Neurochemistry, acupuncture, and epidemiology}

During the first week in the Institute I turned my attention to the neurochemical research that Professor Shen Yucun and Dr Zhang Wen-He are conducting. Their team is engaged upon the task of obtaining a profile of the neurochemical changes associated with schizophrenia. This programme, started in the late fifties, was disrupted in the early sixties by political upheaval. The laboratory was closed for ten years, and staff were sent to the countryside-a fate very common in academic and professional life, which has had a devastating effect on Chinese technology. Despite these problems the laboratory is producing interesting data ${ }^{2}$ and expects to be able to introduce the very latest assays in the near future. As well as reviewing progress, I collaborated with Dr Zhang on one aspect of the programmethe measurement of urinary methoxyhydroxyphenylglycol sulphate (a metabolite of central noradrenaline) in chronic schizophrenics and matched controls. We found a significantly 


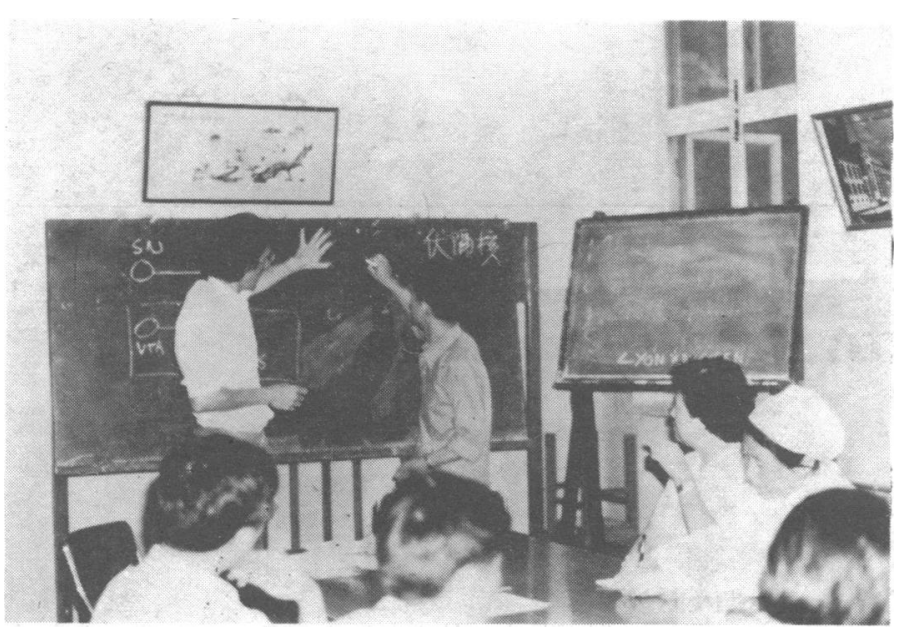

The author giving a Wednesday afternoon lecture at the Institute of Mental Health.

higher level in the chronic schizophrenic group and prepared our findings for publication.

Dr Wang Zuxin, the clinical psychopharmacologist, explained the Chinese approach to treating schizophrenia. As in the West the first line of treatment is neuroleptics, with increasing use of depot preparations. Dr Wang expressed concern at the rising incidence of tardive dyskinesia, for which he advocated gradual withdrawal of the neuroleptics with simultaneous administration of promethazine. It was interesting to find that deep insulin treatment was still used, primarily as a last resort for patients showing no response to other drugs; Dr Wang explained that reasonable results had been achieved; moreover the effect tended to last longer than that achieved by neuroleptics. Of a series of about 200 patients in $1979,20 \%$ had insulin treatment, of these Dr Wang estimated about half make a significant recovery. He thought that this was not accounted for merely by extra interest from the staff.

Dr Luo Hechun whose special interest is traditional Chinese medicine was to show me the results of both electroacupuncture and laser acupuncture for the alleviation of schizophrenic symptoms. The latter was introduced in 1978 and involves focusing a low-power laser $(4.3 \mathrm{mw})$ on to specific acupuncture points. The method is claimed to have distinct advantages: it is noninvasive, faster to administer, seemingly more efficacious, and easier to handle in controlled studies than traditional methods.

I was to find the epidemiological work of Professor Shen Yucun and Dr Zhang Weixi especially interesting. Since 1958 they have been studying the pattern of schizophrenia in a mixed urban and rural population of more than 190000 people. The findings suggest a number of interesting features, for instance, a lower prevalence than WHO population estimates, and a higher prevalence in the urban population and among females. I was particularly impressed that the institute staff not only collected their data but also set up primary mental health care facilities in the countryside by training paramedicals and setting up channels of referral. Further studies are planned with new diagnostic criteria and improved sampling techniques.

Towards the end of my stay in Peking I visited brigade health stations and the commune hospital of the Si Ji Qing commune in the west of Peking. In addition I visited Huei Lung-Guan Hospital, a large sanatorium for the chronic mentally ill. Its director, Dr Weng Yong-Zhen, explained that $95 \%$ of the patients were chronic schizophrenics managed on low-dose phenothiazines. The wards were drab and crowded; many had 80 beds supervised by 15-18 nurses, whose attitude was warm and caring. Admission was by referral from outpatient departments. I was told that there are no formal laws by which patients can be committed. The therapeutic objective was to control the symptoms and then to return the patients to the community.

\section{Peking life}

I found life for medical students in Peking very different from that in Britain. Competition for places is even greater than in Britain, and the sense of commitment to the course is thus correspondingly deeper. Apart from sports extracurricular activities are few. There is even less social activity. There is also little opportunity for contact between the sexes. Accommodation is very crowded, six students to a room being usual. This applies to most people despite the city's active building programme; I was in a country of a thousand million people. While there are some signs of change, it seems that medical students have little say in the development of either their curricular or extracurricular activities. I was, however, impressed by their dedication.

My day at the institute began at 8 am and finished at $6 \mathrm{pm}$. The Chinese break the day with a two-hour lunch period during which they take a nap. The college was alive with activity in the early morning. I was often awoken by the blare of Peking Radio broadcast loudly over the college grounds. Outside men and women of all ages jogged and did static body exercises, student sports teams practised, and, to my ultimate amazement, the army moved in to drill the medical students for two weeks.

It was my habit to spend part of the lunchtime at the college swimming pool; at first this was a daunting experience because of the curiosity I aroused. On one occasion I met the professor of English language from the college, who invited me to talk to a small group of his medical students. I hardly gave his vague invitation another thought, until one evening he came for me looking very excited. "Everyone is waiting" he said. "Everyone ?" I thought. As I walked into the "seminar" I found an audience of 300 awaiting expectantly. Avoid Peking swimming pools.

It was characteristic of the hospitality that my Chinese hosts displayed that every weekend one of the psychiatrists arranged to accompany me to one of the cultural sights in or around Peking. By the time I left, I felt I knew Peking nearly as well as I know London. For in addition to the hospitality of the institute staff, my foreign medical student friends took me by bicycle to interesting parts of the city. Before I was lent a bicycle, I travelled round Peking on the pillion of either my Sudanese or my Philippino friends' bicycles-a common practice in Peking; the locals were, however, surprised to see an African and Englishman pass by. From time to time one encounters a foreign party, recognisable from afar by their outlandish dress and photographic paraphernalia. Such a spectacle rapidly becomes distasteful as one lives and understands the Chinese way of life, though the Chinese themselves always remain welcomingoutwardly at least-to their "foreign friends."

I left Peking indebted to the staff of the institute for making my stay so comfortable and my research so rewarding. I was refreshed by the utilitarianism and high quality of life of my hosts. I returned to England convinced that we have a lot to learn from the Chinese and their society almost free of alcoholism, drug addiction, venereal disease, and delinquency. I hope to return.

I acknowledge the generous support of the regius professor of physic, the Cambridge School of Clinical Medicine, the British Medical Student's Trust, the Gilchrist Educational Trust, the Mental Health Foundation, St John's College, Cambridge, and the Wellcome Trust, without whose help this visit would not have been possible.

\section{References}

1 Horn JS. The Mass Line. London: The Anglo-Chinese Educational Institute, 1978.

2 Shen Yucun, Zhang Wen-He. 5-hydroxytryptamine metabolism in schizophrenics. Chin Med F 1979;92:817-21. 